\title{
Severe microcephaly, intellectual disability and epilepsy: the ravages of congenital syphilis
}

\author{
Arushi Gahlot Saini, ${ }^{1}$ Gautam Kamila, ${ }^{1}$ Sameer Vyas ${ }^{2}$
}

'Department of Pediatrics, Post Graduate Institute of Medical Education and Research, Chandigarh, India ${ }^{2}$ Department of Radiodiagnosis, Post Graduate Institute of Medical Education and Research, Chandigarh, Chandigarh, India

\section{Correspondence to} Dr Arushi Gahlot Saini; doc.arushi@gmail.com

Accepted 24 May 2021

Check for updates

(C) BMJ Publishing Group Limited 2021. No commercial re-use. See rights and permissions. Published by BMJ.

To cite: Saini $A G$, Kamila G, Vyas S. BMJ Case Rep

2021;14:e244203.

doi:10.1136/bcr-2021-

244203

\section{DESCRIPTION}

A 9-year-old girl from North India presented with poor intellect and behavioural abnormalities noticed since early childhood and two episodes of generalised seizures during the past 6 months. There was no history of alteration in sensorium, vision or hearing impairment, waxing and waning, or progressive neurological symptoms, abnormal tone, skin, hair or body odour. She was born at 34 weeks of gestation to an unsupervised, primigravida mother by vaginal delivery and weighed $1.3 \mathrm{~kg}$ at birth. At 12 hours of life, she was noticed to have nasal discharge, poor feeding, lethargy and recurrent apnoea. Her hospital records revealed microcephaly ( $28 \mathrm{~cm},<3 \mathrm{rd}$ centile), hepatosplenomegaly and normal fundi, thrombocytopaenia $\left(64 \times 10^{9} \mathrm{cells} / \mathrm{L}\right)$, transaminitis (alanine transaminase $452 \mathrm{IU} / \mathrm{L}$, aspartate transaminase $897 \mathrm{IU} / \mathrm{L}$ ) and conjugated hyperbilirubinaemia (total bilirubin $9.1 \mathrm{mg} / \mathrm{dL}$, conjugated bilirubin $6.9 \mathrm{mg} / \mathrm{dL}$ ). Blood culture showed growth of coagulase-negative Staphylococcus aureus. Cerebrospinal fluid analysis showed 10 polymorphonuclear cells, elevated protein $(100 \mathrm{mg} / \mathrm{dL})$, glucose $75 \mathrm{mg} / \mathrm{dL}$ (blood glucose $150 \mathrm{mg} / \mathrm{dL}$ ) and no organism on gram stain or culture. Serology for toxoplasma, cytomegalovirus, herpes, rubella and HIV were non-reactive. Infantogram showed irregular areas of increased density and rarefaction and subperiosteal bone deposition in the long bones suggestive of periosteitis (figure 1). Titres for venereal disease research laboratory (VDRL) and Treponema pallidum haemagglutination assay (TPHA) were elevated $(1: 128$ and 1:80, respectively). VDRL tests of both parents were also positive. VDRL, TPHA and specific IgM on cerebrospinal fluid were negative. A diagnosis of congenital syphilis was made and the infant was treated with aqueous penicillin $\mathrm{G}(50000 \mathrm{U} /$ $\mathrm{kg}$ per dose every 12 hours) during the first 7 days and every 8 hours till day 14 . Both parents were administered single-dose intramuscular benzathine penicillin. A repeat VDRL test at 3 months of age showed reactive titres (1:4). Repeat cerebrospinal fluid analysis showed 10 polymorphonuclear cells, protein $20 \mathrm{mg} / \mathrm{dL}$, glucose $45 \mathrm{mg} / \mathrm{dL}$ (blood glucose $80 \mathrm{mg} / \mathrm{dL}$ ), non-reactive VDRL test and no organism on gram stain or culture. A repeat course of intravenous crystalline penicillin for 14 days was instituted. She remained well subsequently and presented to us with her current neurological concerns. Examination showed microcephaly $(45 \mathrm{~cm},<-3 \mathrm{z})$, left-sided exotropia, mild optic atrophy and severely impaired intelligence quotient (IQ 27). MRI of the brain showed bilateral occipital

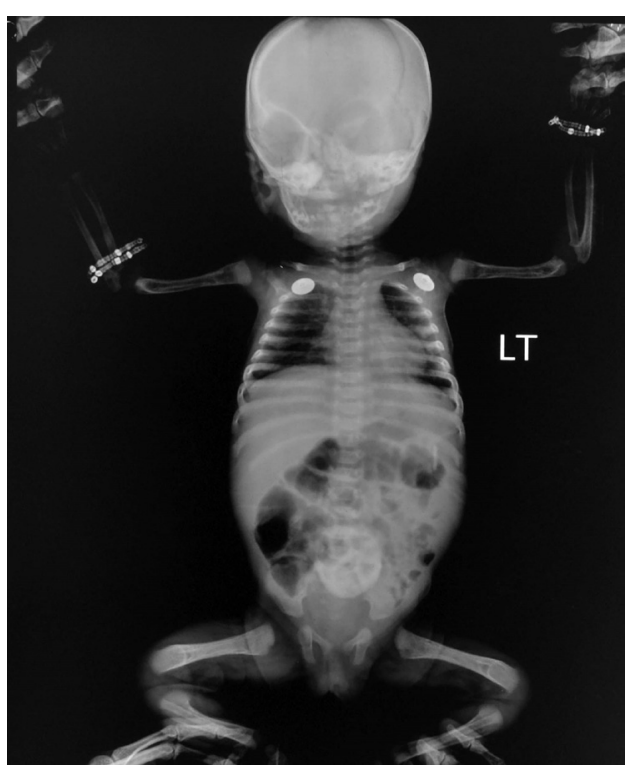

Figure 1 Infantogram in the index patient on day 2 of life showing irregular areas of increased density and rarefaction in the long bones suggestive of moth-eaten appearance.

gliosis and colpocephaly (figure 2A-D). Electroencephalograph, visually evoked responses and brain stem evoked auditory responses were normal. She was initiated on oral phenytoin $(5 \mathrm{mg} / \mathrm{kg} /$ day $)$ and rehabilitation with special schooling.

Congenital syphilis has been recognised as a disease of significant health importance. According to the recent global and regional estimates of maternal and congenital syphilis, the global maternal syphilis prevalence rate was $0.69 \%$ and the estimated congenital syphilis case rate was 473 cases per lakh live births in $2016 .{ }^{1}$ The highest rates are in Africa, followed by the regions of America and the eastern Mediterranean region. ${ }^{1}$ In comparison, the South-East Asian region showed a lower maternal syphilis prevalence rate $(0.21 \%)$ and a lower estimated congenital syphilis case rate (145 cases per lakh live births). ${ }^{1}$ The exact incidence of congenital syphilis in India is not known, the estimated incidence was 0.6 cases per 1000 live births in 2012. ${ }^{2}$ Despite the global and regional differences, this preventable cause of neurodisability is not completely eliminated and often escapes a timely diagnosis or treatment. The primary mode of transmission of the spirochete T. pallidum subspecies pallidum is transplacental and rarely during childbirth. It can result in late spontaneous abortion, stillbirth, prematurity and clinical manifestations at birth in severe cases. Early congenital syphilis may 


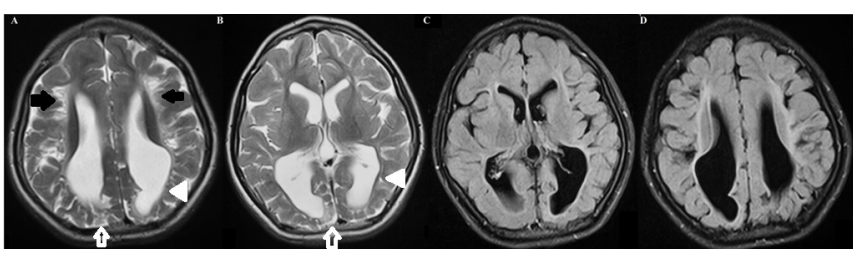

Figure $2 \mathrm{MRI}$ of the brain done at 9 years of age in the index patient showing $(A-B)$ axial and $(C-D)$ fluid-attenuated inversion recovery (FLAIR) sections showing bilateral occipital gliosis (white arrow), abnormal hyperintensities (black arrows) and volume loss in periventricular white matter causing undulated ventricular outline and colpocephaly (dilatation of the occipital horns of the ventricles, white arrowhead).

manifest as non-immunologic hydrops fetalis, failure to thrive, jaundice, hepatitis, hepatosplenomegaly, anaemia, thrombocytopaenia, renal failure, rhinitis, interstitial pneumonia, chondritis, hoarseness of voice, maculo-vesiculo-papular rash and hypothyroidism. Several of these features were important clinical clues in our patient. Early signs of involvement of the nervous system include meningitis and hydrocephalus, following which the child may develop global developmental delay, sensorineural hearing loss and psychomotor disturbances. Involvement of the skeletal system gives additional bedside clues to the diagnosis such as osteochondritis or perichondritis, periosteitis and diaphyseal osteomyelitis. ${ }^{3}$ Late stigmata of congenital syphilis include saddle nose, sabre shin, notched incisors and malformed molars, interstitial keratitis and syphilitic retinitis. These occur due to the chronic inflammation and scarring if infants are not treated at all or are treated late. ${ }^{4}$

All portions of the central nervous system are equally vulnerable to the ravages of syphilis. MRI abnormalities are variable, with most of them showing diffuse cerebral atrophy and temporal lobe changes, and they mimic many other neurological disorders. In the index case, the white matter changes and intellectual impairment may also be contributed by the prematurity although our child did not have any tone changes or classical spastic diplegia associated with prematurity-related white-matter insult. In a Brazilian study of neonates with congenital syphilis and follow-up from birth up to 5 years, congenital syphilis was associated with still births, preterm delivery ( $<34$ weeks), low birth weight and small for gestational age. ${ }^{5}$ Only one-third of the patients could be followed up between 8 and 60 months, and the majority showed good outcomes when treated adequately; nearly $1 / 10$ of the cases showed sequelae..$^{5}$ Thus, congenital syphilis remains an impacting disease throughout the life of a newborn. The diagnosis and management of suspected cases is challenging, and there is a high potential for severe disability in missed and inadequately treated cases. Long-term follow-up to assess the true burden of the neurological disability is needed. Hence, paediatricians should consider congenital syphilis in any infant with suspicious clinical findings, despite maternal serological status. All pregnant mothers should be screened for syphilis during the pregnancy and no mother or infant should be discharged from a birth hospital without a documentation of the maternal syphilis status.

\section{Learning points}

Congenital syphilis is a preventable and treatable disease entity.

- Diagnosis and management of suspected neonates is challenging.

- Neurological and radiological manifestations of congenital syphilis in later life are less commonly described.

Contributors AGS: draft of manuscript, GK: draft of manuscript, SV: radiological review.

Funding The authors have not declared a specific grant for this research from any funding agency in the public, commercial or not-for-profit sectors.

Competing interests None declared.

Patient consent for publication Obtained.

Provenance and peer review Not commissioned; externally peer reviewed.

\section{REFERENCES}

1 Korenromp EL, Rowley J, Alonso M, et al. Global burden of maternal and congenital syphilis and associated adverse birth outcomes-Estimates for 2016 and progress since 2012. PLoS One 2019;14:e0211720.

2 World Health Organization. The National strategy and operational guidelines towards elimination of congenital syphilis, 2015. published by NACO under Ministry of health and family welfare and who. Available: http://www.naco.gov.in

3 Nagappa M, Sinha S, Taly AB, et al. Neurosyphilis: MRI features and their phenotypic correlation in a cohort of 35 patients from a tertiary care university hospital. Neuroradiology 2013;55:379-88.

4 Cooper JM, Sánchez PJ. Congenital syphilis. Semin Perinatol 2018;42:176-84.

5 Lago EG, Vaccari A, Fiori RM. Clinical features and follow-up of congenital syphilis. Sex Transm Dis 2013;40:85-94.

Copyright 2021 BMJ Publishing Group. All rights reserved. For permission to reuse any of this content visit

https://www.bmj.com/company/products-services/rights-and-licensing/permissions/

BMJ Case Report Fellows may re-use this article for personal use and teaching without any further permission.

Become a Fellow of BMJ Case Reports today and you can:

- Submit as many cases as you like

- Enjoy fast sympathetic peer review and rapid publication of accepted articles

- Access all the published articles

Re-use any of the published material for personal use and teaching without further permission

Customer Service

If you have any further queries about your subscription, please contact our customer services team on +44 (0) 2071111105 or via email at support@bmj.com.

Visit casereports.bmj.com for more articles like this and to become a Fellow 